\title{
DESIGN OF A LOW COST WIRELESS ACQUISITION SYSTEM FOR HUMAN VIBRATION MEASUREMENT IN HARSH ENVIRONMENTS
}

\author{
Pierre Marcotte $^{* 1}$, Sylvain Ouellette ${ }^{2}$, Jérôme Boutin ${ }^{1}$, Gilles LeBlanc ${ }^{2}$ \\ ${ }^{1}$ IRSST, 505 boul. de Maisonneuve West, Montréal, QC, H3A 3C2, Canada \\ ${ }^{2}$ CANMET Mining and Mineral Sciences Laboratories, Val-d'Or, Canada
}

\section{Introduction}

In order to perform multichannel time signal acquisition in harsh environments like underground mines, where there is a high risk of having the equipment damaged or destroyed, it is convenient to use a robust low cost system that allows remote control and monitoring. Such a system has been developed and successfully tested in underground mines for human vibration assessment, and will be presented in this abstract.

\section{Methods}

The acquisition system is composed of two National Instrument NI-9234 USB boards (IEPE, 24 bits), giving a total of 8 channels, an external LI-ON battery, one minicomputer with solid-state hard disk for added robustness, and a small waterproof Pelican ${ }^{\mathrm{TM}}$ case. Pictures of the acquisition system are shown in Fig. 1. The system had to be very compact in order to be installed on certain equipment where the space was very limited (see Fig. 1, right). The acquisition process was implemented under LabVIEW ${ }^{\mathrm{TM}}$, with two different sampling rates for hand-arm $(5120 \mathrm{~Hz})$ and whole-body vibration $(512$ $\mathrm{Hz}$ ). Using the "Remote desktop" function of Windows $\mathrm{XP}^{\circledR}$, a second laptop computer was used to wirelessly control and monitor (time signals and spectra) the acquisition process. The IEPE mode of the NI-9234 boards was used to supply electrical power to the accelerometers, requiring the use of AC coupling. Since the NI-9234 board has, in AC coupling, a roll-off of $3 \mathrm{~dB}$ at $0.5 \mathrm{~Hz}$, a digital FIR filter was added to correct the low
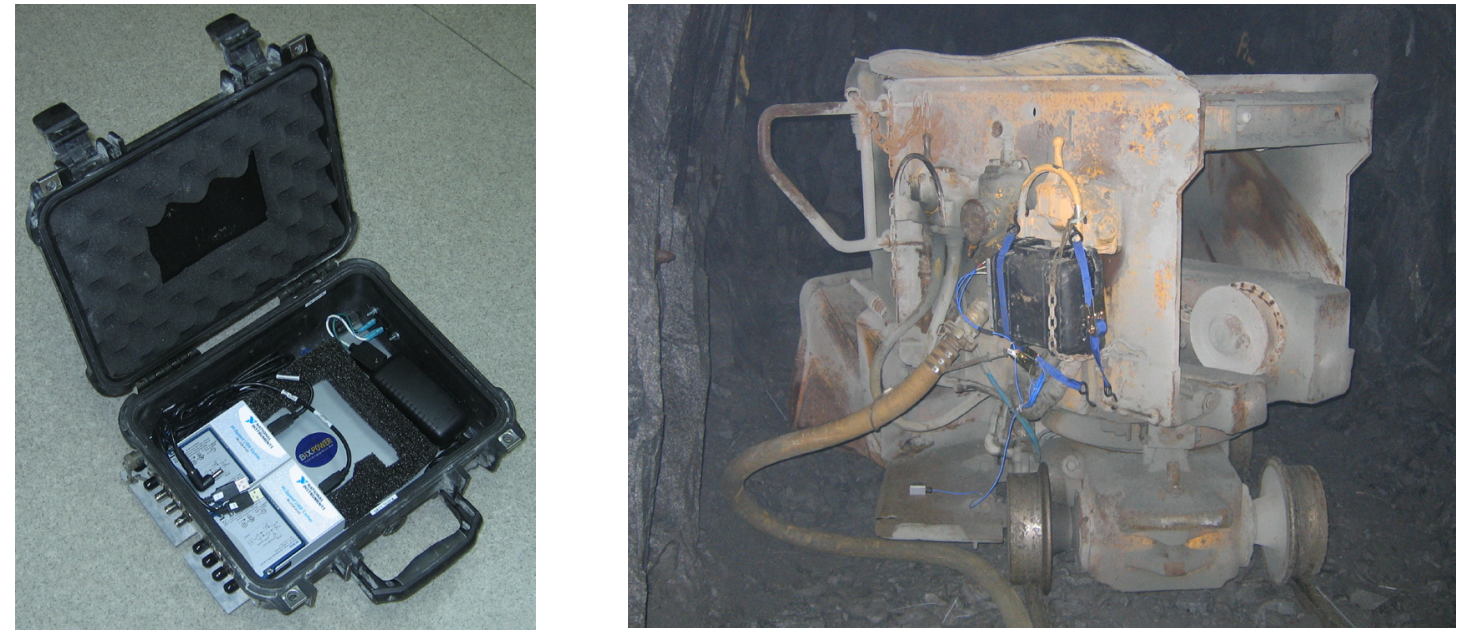

Fig. 1: Acquisition system without the mini Laptop in order to show the components (left), acquisition system and accelerometer installed on muck machine (right). 
frequency response in whole-body vibration measurement mode, in order to satisfy the newer standard ISO 8041:2005 ${ }^{1}$. In addition, it has been shown that low frequency components can have a significant effect on WBV metrics ${ }^{2}$. The digital FIR filter coefficients for the sampling rate of $512 \mathrm{~Hz}$ were calculated using the FIR2 function of MATLAB ${ }^{\circledR}$. The target frequency response of the filter was the measured compensation needed to achieve a flat response in the entire frequency range. In practice, compensation was only needed between 0 and $6.3 \mathrm{~Hz}$. A total of 2000 coefficients were used for the FIR filter.

\section{Results}

Fig. 2 shows the compensation achieved by the FIR filter (filter gain) in the low frequency range, with the lower and upper limits being the target gain $\pm 1 \mathrm{~dB}$. It is further shown that the filter satisfy the ISO $8041: 2005^{1} \pm 2 \mathrm{~dB}$ tolerance at $0.315 \mathrm{~Hz}$. The digital filter has a linear phase (not show in the figure), which translates to a delay in the time domain. It was possible to implement the filter in real time during the acquisition of the time signal. The system has been validated using electrical signals and different known vibration levels. It also has been successfully used to measure human vibration in 8 underground mines on 24 different mining equipments.

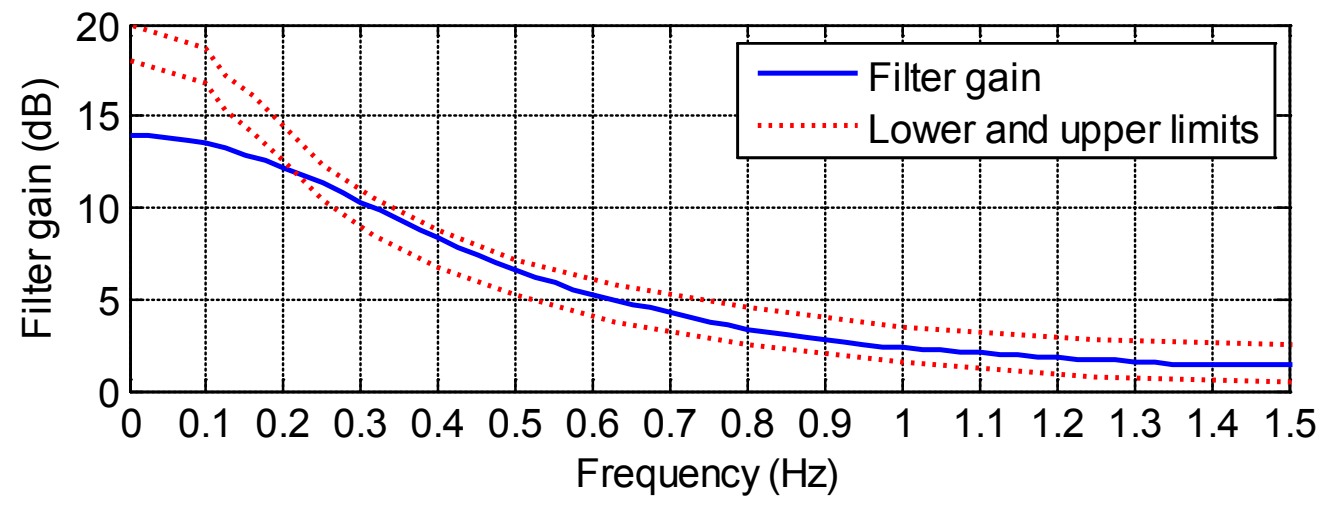

Fig. 2: Filter gain, also showing the $\pm 1 \mathrm{~dB}$ tolerance (lower and upper limit).

\section{Discussion}

A low cost wireless acquisition system has been built to perform time signal acquisition in harsh environment like underground mines. The system has been validated and successfully used to assess human vibration in different underground mines.

\section{References}

1. ISO 8041:2005, Human response to vibration - Measuring instrumentation, International Organization for Standardization, Geneva, Switzerland.

2. L. Notini, N.J. Mansfield, G.S. Newell, An assessment of the contribution of earth moving machine WBV components below $1 \mathrm{~Hz}$ to ISO 2631-1 and ISO 2631-5 metrics, Proceedings of the $41^{\text {st }}$ UK group meeting on human response to vibration, Farnborough, Hampshire, England, 20-22 Septembre 2006. 